\title{
Assessment of the operating windows of a combined solidification/stabilization and granulation treatment applied to industrial soil in the context of brownfield regeneration
}

\author{
O. Capobianco, G. Costa \& R. Baciocchi \\ Department of Civil Engineering and Computer Science Engineering, \\ University of Rome 'Tor Vergata', Italy
}

\begin{abstract}
This work reports the results of a lab-scale investigation carried out to assess the effects of a stabilization/solidification-granulation treatment applied to an industrial soil sampled from a brownfield site. Preliminary tests were performed on a natural soil to investigate the effects of the operating conditions and mixture formulations on the physical and mechanical properties of the product. In a second phase, the process was tested on the brownfield industrial soil, applying the operating conditions and binder type that provided the best results in the preliminary tests. The suitability of the obtained granules for use as artificial aggregates was assessed through the analysis of the particle size distribution, mechanical strength and inorganic contaminant leaching. With regard to the industrial soil, the best mechanical performance, comparable to that of natural gravel, was achieved with the following mixture formulation: $30 \% \mathrm{wt}$. of cement $\mathrm{R} 52.5$, a water/solid ratio equal to $0.14 \mathrm{l} / \mathrm{kg}$ and an additive/solid ratio equal to $2 \% \mathrm{wt}$. The alkaline $\mathrm{pH}$ of the leachates as well as the leaching behaviour of the cement showed to exert a great influence on the release of some critical metals from the obtained granules, such as $\mathrm{Ba}, \mathrm{Cr}$, $\mathrm{Mo}$ and $\mathrm{Cu}$.

Keywords: brownfields, technology trains, operating windows, aggregates, mechanical properties, inorganic contaminants, leaching.
\end{abstract}

\section{Introduction}

The modification of land use and the subsequent dismantling of several industrial activities have led to the formation of a number of derelict or underused sites, i.e. brownfields, all across Europe that are waiting to be reintroduced within the 
so called Land Management Cycle. One of the main factors that hinders the revitalization of brownfield sites is the need to address soil contamination issues, which may arise from the past land activities as well as from the interim uses of the site. Partly also as a consequence of the lack of a clear requalification pathway, the clean-up step is decoupled from the requalification one. This often leads to a preliminary clean-up performed with a technology chosen in order to prepare the site for a specific use or simply to comply with the current environmental legislation. In this "bottom-up" approach, traditional remediation strategies, e.g. excavation and landfilling, are generally applied for the management of the contaminated soil, implying off-site transport and leading to further land consumption. From a different perspective, the environmental issues associated with a brownfield site could be seen as an opportunity to provide products or services for the site itself and the surrounding area. The clean-up of the site, which is mandatory for the reintroduction of a brownfield within the land cycle, should be fulfilled by (re)using material and exploiting resources already present at the site and/or produced as a result of the regeneration activities themselves $[1,2]$. This aim can be potentially achieved by coupling different technologies, i.e. by applying a specifically tailored technology train to the contaminated material present at a brownfield site in order to obtain a product that can be reused within the site itself or in nearby sites where such a service is required.

A potentially interesting management strategy for industrial soil in a Brownfield regeneration context consists in its treatment to produce aggregates for construction purposes, e.g. in concrete production, since this practice may allow to avoid landfilling as well as to reduce the consumption of virgin raw material. In addition, industrial soils originating from abandoned industrial sites may cause detrimental environmental effects related to the release of toxic metals and metalloids into the environment [3]. Therefore, the proposed treatment should also reduce the mobility of potential contaminants. Often, this goal is achieved through a stabilization/solidification $(\mathrm{S} / \mathrm{S})$ process, which involves the controlled addition and mixing of hydraulic binders with contaminated soils to form a monolith showing an improved environmental behaviour and high mechanical resistance $[3,4]$. In spite of this, the application of $\mathrm{S} / \mathrm{S}$ treatments does not allow to obtain a product with a suitable particle size to be reused in substitution of natural aggregates in civil applications. Granulation processes may be applied to obtain a significant particle size enlargement, which is achieved by mixing a liquid binder with a fine particle size material in a rotary drum or similar device $[5,6]$. Recently, a number of studies have focused on the coupling of the two above mentioned techniques in order to obtain aggregates from the treatment of several waste material, such as contaminated soil [7], municipal solid waste incinerator bottom [8] and fly ash $[9,10]$, automotive shredder residues [11]. It was proved that such a treatment may be effective in obtaining pellets with sufficient mechanical strength to be reused in civil engineering applications and exhibiting a decreased release of toxic elements, such as $\mathrm{As}, \mathrm{Pb}, \mathrm{Cd}$ and $\mathrm{Hg}$ [7]. 
This work is the first step towards the assessment of the conditions of applicability, i.e. operating windows, of a technology train employing the above mentioned combined techniques and aiming at producing aggregates to use in construction applications from industrial soil. The proposed approach appears to be particularly relevant in a brownfield regeneration context, since it may potentially allow the decrease of landfilling, save natural resources and make brownfields redevelopment more viable and sustainable.

In particular, the selected technology train consists in a grain size screening step in which the material is separated into two size fractions, followed by the treatment of the fine fraction by the combined stabilization/solidification and granulation process. The aim of this treatment is to obtain a product with a grain size above $2 \mathrm{~mm}$, characterized by both mechanical and environmental properties suitable to be used as an aggregate in construction applications. In order to gain a first insight on the operating windows of this process, a lab-scale investigation was first performed on a natural soil, by varying the operating conditions and the type and amount of binder and additive. In a subsequent phase, a second set of experiments was carried out on an industrial soil sampled from a brownfield site, selecting the operating conditions and binder type that provided the best results in terms of mechanical strength in the preliminary tests.

\section{Materials and methods}

\subsection{Materials}

The industrial soil used in this study was sampled from an Italian brownfield site located in central Italy that hosted a cotton and wool manufacturing plant up to the early 30's. A non-contaminated natural soil was also tested in order to assess the influence of the composition of the mixture on the mechanical strength of the final product. After determining the particle size distribution of the materials (ASTM D422), the coarser fraction was discarded, while the finer fraction of both materials $(\mathrm{d}<2 \mathrm{~mm})$, corresponding to $66 \% \mathrm{wt}$. and $49 \% \mathrm{wt}$. of the natural and industrial soil, respectively, was characterized in terms of its main chemical constituents, by acid digestion of air dried soil samples, following the standard procedure EPA $3050 \mathrm{~b}$, and analysing the obtained solutions by inductively coupled plasma optical emission spectrometry (ICP-OES). Total organic carbon (TOC) was assessed by using a Shimadzu TOC VCPH analyser equipped with a solid sample module by applying the standard procedure EN 13137.

The elemental composition of the industrial soil is reported in Table 1 together with the regulatory limits set by the Italian legislation for residential use that is foreseen for the new destination of the site. As shown in Table 1, the major constituents of the industrial soil included $\mathrm{Fe}, \mathrm{Al}, \mathrm{Ca}, \mathrm{Mg}$ and $\mathrm{Na}$. Regarding the regulated elements, appreciable concentrations of $\mathrm{Cu}, \mathrm{Ba}, \mathrm{Zn}, \mathrm{Pb}$, $\mathrm{Sn}$ and $\mathrm{Hg}$ were observed. Specifically, $\mathrm{Cu}, \mathrm{Pb}, \mathrm{Hg}$ and $\mathrm{Sn}$ concentrations exceeded the relative Italian threshold values for residential use. The natural soil was mainly constituted by $\mathrm{Al}(20 \mathrm{wt} \%), \mathrm{Na}(4.4 \mathrm{wt} \%), \mathrm{Ca}(3.4 \mathrm{wt} \%)$ and Fe $(2.9 \mathrm{wt} \%)$ and its concentration of regulated elements, not shown for sake of brevity, proved to be lower, as expected, than that of the industrial soil. The TOC 
content of the industrial soil was around $1.2 \mathrm{wt} \%$, while the natural soil seemed to be free of organic matter with a TOC content below the instrumental quantification limit.

Table 1: Main composition of the fine fraction $(\mathrm{d}<2 \mathrm{~mm})$ of the industrial soil ( $\mathrm{mg} / \mathrm{kg}$ dry wt.). The relative regulatory limits for residential use are shown in brackets (Italian Legislative Decree 152/06).

\begin{tabular}{|c|c|c|c|}
\hline Element & Measured conc. (Limits) & Element & Measured conc. (Limits) \\
\hline $\mathrm{Fe}$ & 12400 & $\mathrm{Ni}$ & $43.57(120)$ \\
\hline $\mathrm{Al}$ & 7807 & $\mathrm{Cr}$ & $34.37(150)$ \\
\hline $\mathrm{Ca}$ & 4230 & $\mathrm{~K}$ & 22.56 \\
\hline $\mathrm{Mg}$ & 3762 & $\mathrm{~V}$ & $17.07(90)$ \\
\hline $\mathrm{Na}$ & 1283 & $\mathrm{Li}$ & 10.06 \\
\hline $\mathrm{Cu}$ & $475(120)$ & $\mathrm{As}$ & $8.69(20)$ \\
\hline $\mathrm{Mn}$ & 475 & $\mathrm{Co}$ & $1.97(20)$ \\
\hline $\mathrm{Si}$ & 221 & $\mathrm{Sb}$ & $1.95(10)$ \\
\hline $\mathrm{Ba}$ & 152 & $\mathrm{Mo}$ & 1.15 \\
\hline $\mathrm{Zn}$ & $129(150)$ & $\mathrm{Be}$ & $1.13(2)$ \\
\hline $\mathrm{Pb}$ & $105(100)$ & $\mathrm{Hg}$ & $1.02(1)$ \\
\hline $\mathrm{Sn}$ & $43.85(1)$ & $\mathrm{Cd}$ & $0.48(2)$ \\
\hline
\end{tabular}

\subsection{Methods}

The S/S-granulation experiments were performed in a laboratory scale granulator with a diameter of $0.3 \mathrm{~m}$ and a height of $0.23 \mathrm{~m}$, equipped with a blade to promote granules formation, operated at $24 \mathrm{rpm}$ for 5-10 minutes, with a tilt of $66^{\circ}$. The rotation speed, the granulator inclination, as well as the duration of the tests were selected by performing preliminary optimization experiments on the natural soil, the results of which are not reported in this paper.

A high resistance Portland cement (CEM I 52.5R) and a Portland composite cement (CEM II/A-LL 42.5 R) were tested as binders, while sulfonate-based (A1) or acrylic-based (A2) superplasticizers were employed as additives, in order to decrease the amount of required water and possibly improve the mechanical performance of the product. For each S/S-granulation experiment, approximately $500 \mathrm{~g}$ of air dried soil and cement were preliminary mixed with the deionized water, or with a solution containing water and additive, in a plastic bag before being inserted into the granulator. The preliminary screening tests on the natural soil were carried out by varying the water/solid ratio (W/S), cement/solid ratio $(\mathrm{C} / \mathrm{S})$ and additive/cement ratio $(\mathrm{A} / \mathrm{C})$, in order to gain a first insight on the operating windows of the process and study the influence of the different parameters on the process performance. Based on the results of these tests, S/Sgranulation experiments were performed on the industrial soil, employing the mixture formulations that provided the best results in terms of the achieved particle size distribution and mechanical resistance.

The obtained granules were cured for 28 days at room temperature and $100 \%$ relative humidity and subsequently tested for assessing their suitability to 
be reused in construction applications through the analysis of the particle size distribution, mechanical strength and inorganic contaminant leaching.

The mechanical strength of the granules was evaluated by performing the Aggregate Crushing Value (ACV) test, applying the British standard BS 812-110. The leaching behaviour of the untreated industrial soil and cured granules was determined by performing the standard compliance leaching test EN 12457-2, followed by ICP-OES analysis of eluate concentrations. Specifically, the test was performed both on crushed granules $(\mathrm{d}<4 \mathrm{~mm})$ in order to comply with standard specifications, as well as on uncrushed ones, in order to evaluate the effective release of contaminants from the granules obtained as a result of the $\mathrm{S} / \mathrm{S}$-granulation treatment.

\section{Results and discussion}

\subsection{Initial tests on natural soil to assess the optimum mixture formulation}

The main results obtained from the S/S-granulation treatment carried out on the natural soil are shown in Figure 1 and Figure 2.

Figure 1 reports the particle size distribution curves of the granules as a function of the different mixture formulations tested.

The obtained granules showed a particle size mostly comprised between 2.36 and $25 \mathrm{~mm}$ and an average $\mathrm{d}_{50}$ between 6 and $10 \mathrm{~mm}$, one order of magnitude greater than that of the untreated natural soil (about $0.5 \mathrm{~mm}$ ). In Figure 1A the influence of the employed W/S ratio on granule size is reported. As can be noted, the average particle size increased with increasing water content, confirming the results of previous studies on granulation processes [5]. In Figure 1B, the particle size distribution of the manufactured granules is shown as a function of the cement content. For both cements, the average diameter of the granules varied proportionally with the binder content, this effect being more pronounced for cement R 52.5. As shown in Figure 1C, the use of the additives allowed to obtain finer aggregates, especially when using the sulfonate-based superplasticizer in combination with cement $R$ 42.5. This behaviour is consistent with the results of previous studies indicating that a more viscous binder generally leads to the reduction of the granules consolidation rate and subsequently of the compaction and growth of the granules [5].

In order to possibly evaluate the influence of the additive content on the particle size distribution of the final granules, S/S-granulation tests were carried out varying the amount of acrylic-based superplasticizer. Results showed that an increase of the acrylic-based additive amount from 1 to $2 \%$ by weight did not imply any appreciable modification of the particle size distribution of the obtained granules, regardless of the type of cement used as a binder.

The main results in terms of the mechanical resistance of the final product are reported in Figure 2. By comparing Figure 1 and Figure 2, it can be noted that larger particles generally showed a poorer mechanical strength when subjected to the ACV test. 



Figure 1: Comparison of the particle size distribution curves of the as received natural soil and of the granules obtained after the S/S-granulation treatment for cement R 52.5 and cement R 42.5 as a function of: (A) water content ( $\mathrm{C} / \mathrm{S}=30 \% \mathrm{wt}$.); (B) cement content at optimum water content; (C) additive type at optimum water content $(\mathrm{C} / \mathrm{S}=30 \%$ wt. $)$; (D) additive content at optimum water content ( $\mathrm{C} / \mathrm{S}=30 \%$ wt.). 
The influence of the water content on the ACV is reported in Figure 2A. For both cements, the lowest $\mathrm{ACV}$, corresponding to a higher resistance to compression, was achieved at a W/S ratio value of $0.171 / \mathrm{kg}$ and was found to be 41 and $23 \%$ for cement R 42.5 and R 52.5, respectively. As expected, products with higher strength were obtained using cement $\mathrm{R} 52.5$, which presents an intrinsic superior mechanical performance compared to the other type of cement. In addition, for cement $\mathrm{R} 52.5$, a linearly increasing trend of ACV with the water content was noted. With regard to the influence of the binder content on the final mechanical resistance of the granules, the best results were obtained at a $\mathrm{C} / \mathrm{S}$ ratio of $25 \%$ wt (see Figure $2 \mathrm{~B}$ ). At this binder content, an optimum ACV equal to 20 and $28 \%$ was obtained for cement R 52.5 and R 42.5, respectively. The use of either type of additive did not imply any relevant improvement of the mechanical performance of the granules manufactured with cement $\mathrm{R} 52.5$, as highlighted in Figure 2C. Conversely, the mechanical performance of the granules produced with cement R 42.5 was positively influenced by both types
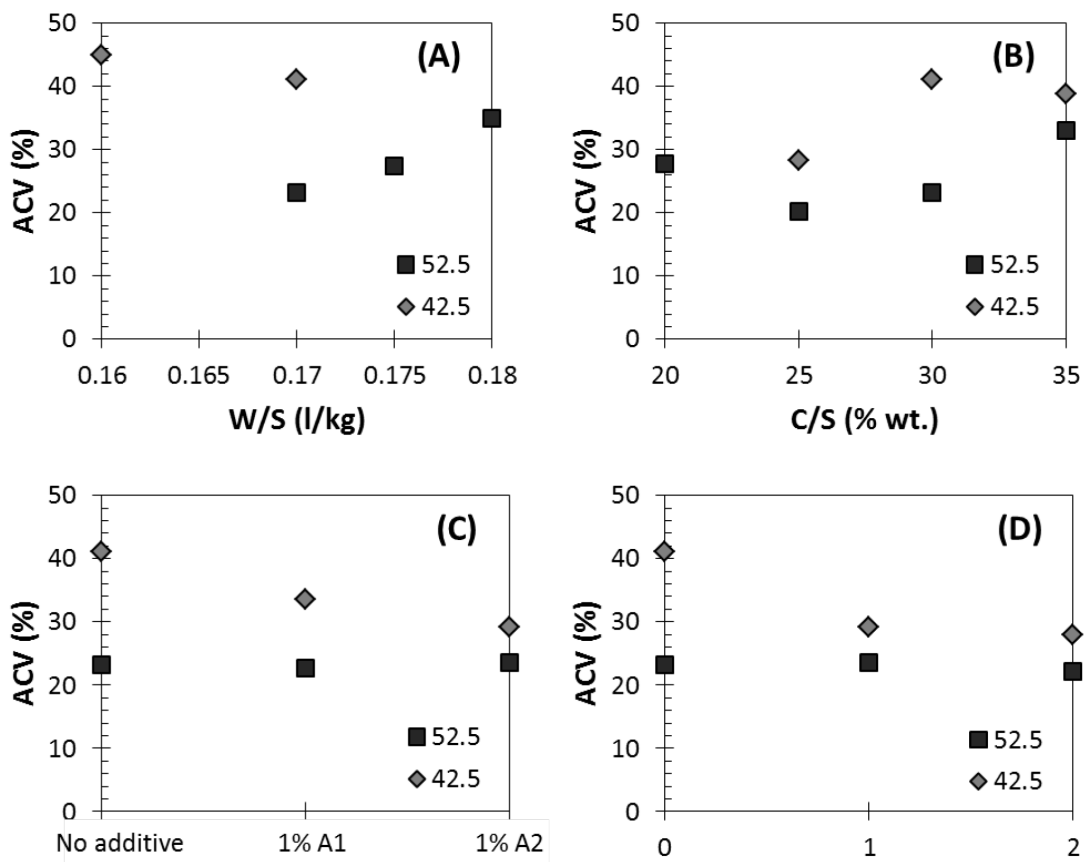

Additive type

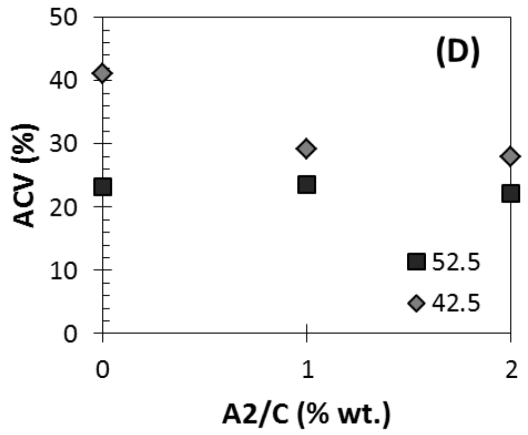

Figure 2: Results of the Aggregate Crushing Value (ACV) test for cement R 52.5 and cement $\mathrm{R} 42.5$ as a function of: (A) water content $(\mathrm{C} / \mathrm{S}=30 \%$ wt. $)$; (B) cement content at optimum water content; (C) additive type at optimum water content $(\mathrm{C} / \mathrm{S}=30 \% \quad \mathrm{wt}$.$) ; (D) additive content at optimum water$ content (C/S $=30 \%$ wt. $)$. 
of additive, especially A2, which allowed to reach the minimum ACV of $29 \%$. It should be noted that this result is very close to that obtained without additives and employing a lower cement content (see Figure 2B). A similar behaviour was observed also increasing the content of the acrylic-based additive, as reported in Figure 2D, i.e. no effects for cement $\mathrm{R} 52.5$, while an enhancement of the mechanical performance of the product for higher amounts of additive using cement R 42.5. Anyhow, it should be pointed out that for both types of cement the use of the additives allowed to reduce the $\mathrm{W} / \mathrm{S}$ ratio down to $0.14 \mathrm{l} / \mathrm{kg}$, this value also being the upper limit for which appreciable increases of the granules resistance were achieved.

\subsection{Tests on industrial soil}

A few of the mixture formulations for which aggregates with a suitable mechanical performance for use in construction were obtained from the natural soil were selected to test the $\mathrm{S} / \mathrm{S}$-granulation treatment on the industrial soil. The results obtained are reported in the following paragraphs, discussing separately the performance in terms of the mechanical properties and of the environmental behavior of the obtained granules.

\subsubsection{Effects of the treatment on particle size and mechanical strength of the obtained granules}

The results in terms of the particle size distribution and ACV of the produced granules are reported in Figure 3A and Figure 3B, respectively. As shown in Figure $3 \mathrm{~A}$, the particle size distribution of the product was slightly more uniform than that observed for the natural soil, showing an average diameter ranging between 5 and $8 \mathrm{~mm}$. This result was probably due to the differences in the initial particle size distribution of the two materials, that of the industrial soil showing to be more uniform than that of the natural soil. Similarly to the natural soil, the use of a more viscous liquid obtained by adding the acrylic-based superplasticizer, allowed to produce finer pellets, in agreement with the findings of Iveson et al. [5].

Regarding the mechanical resistance of the resulting granules, the ACV showed to decrease with increasing binder and additive contents, reaching an optimum value of $20 \%$, which is between that of carboniferous limestone and mixed gravel, for the following mixture formulation: $\mathrm{C} / \mathrm{S}=30 \%$, $\mathrm{W} / \mathrm{S}=0.14 \mathrm{l} / \mathrm{kg}, \mathrm{A} 2 / \mathrm{C}=2 \%$. Hence, differently from the natural soil, for this type of material the use of the acrylic additive and especially of a higher cement content appeared to yield a noteworthy improvement on the mechanical properties of the product. The differences noted on the effects of the binder composition may be tentatively related to the higher TOC content of the industrial soil compared to that of the natural soil. In fact, previous works regarding the stabilization/solidification of waste materials have reported that a TOC greater than $1 \%$ can interfere with the solidification of the cementitious binder as well as with the mechanical resistance of the final product [12]. 

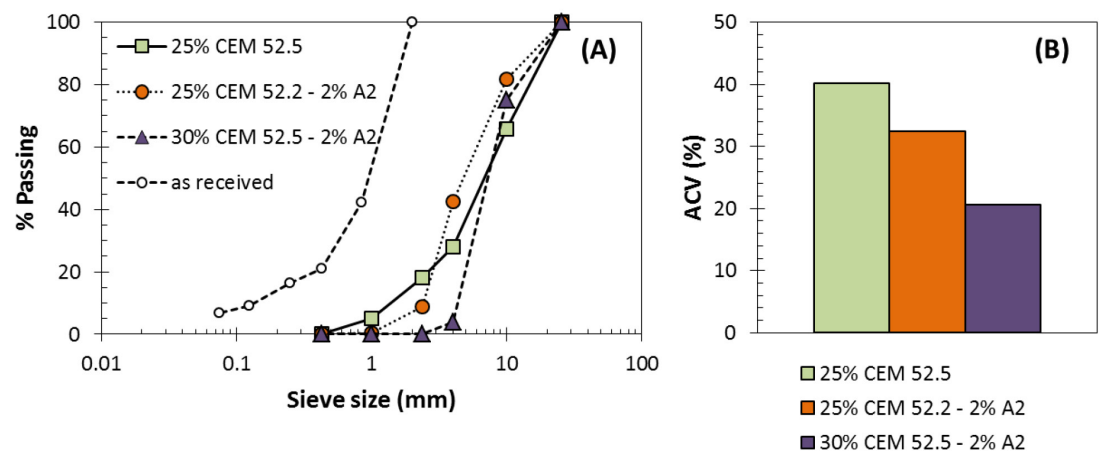

Figure 3: Effects of the $\mathrm{S} / \mathrm{S}$-granulation treatment on the properties of the industrial soil for three mixture conditions in terms of: (A) Particle Size Distribution and (B) Aggregate Crushing Value (ACV).

\subsubsection{Effects of the treatment on the leaching behaviour of the obtained granules}

Despite the presence of relevant concentrations of $\mathrm{Sn}, \mathrm{Pb}$ and $\mathrm{Hg}$ in the as received soil, the concentrations of these elements in the eluates obtained applying the standard leaching compliance test to both untreated and treated soil resulted to be negligible, lower than instrumental quantification limits. The S/Sgranulation treatment yielded a $\mathrm{pH}$ increase from a value of 8.3 to alkaline values of 11.6 and 11.9 for the uncrushed and crushed samples, respectively, due to the addition of the cement $(\mathrm{pH}=12.2)$. In spite of this, $\mathrm{pH}$ values still remained within the limits prescribed by the Italian regulation for material reuse $(5.5<\mathrm{pH}<12)$. Further results of the leaching test carried out on the untreated industrial soil and on both crushed and uncrushed aggregates are reported in Figure 4. In the same figure, the results of the compliance leaching test performed on cement R 52.5 are reported for comparison, together with the limits imposed by the Italian regulation for reuse in simplified procedure (Italian Ministerial Decree 186/06) and disposal in inert waste landfills (Italian Ministerial Decree 27/09/10).

From Figure 4 it can be observed that the concentrations of $\mathrm{Ba}$ in the eluates of the treated soil were significantly higher than in the leachates of the untreated soil, in particular for crushed samples. This result was attributed to an adverse effect of the cement employed as binder in the S/S-granulation experiments. Indeed, remarkable concentrations of $\mathrm{Ba}$ were released from cement $\mathrm{R} 52.5$, even exceeding the regulatory limits established by the Italian legislation for reuse in simplified procedure and disposal in inert waste landfills. Similarly to $\mathrm{Ba}$, the increase of Mo leaching, of up to $42 \%$ of that of the as received material for the crushed pellets, was ascribed to the effect of the cement, which leached Mo in notable concentrations, even higher than the limit imposed for disposal in inert waste landfills. 


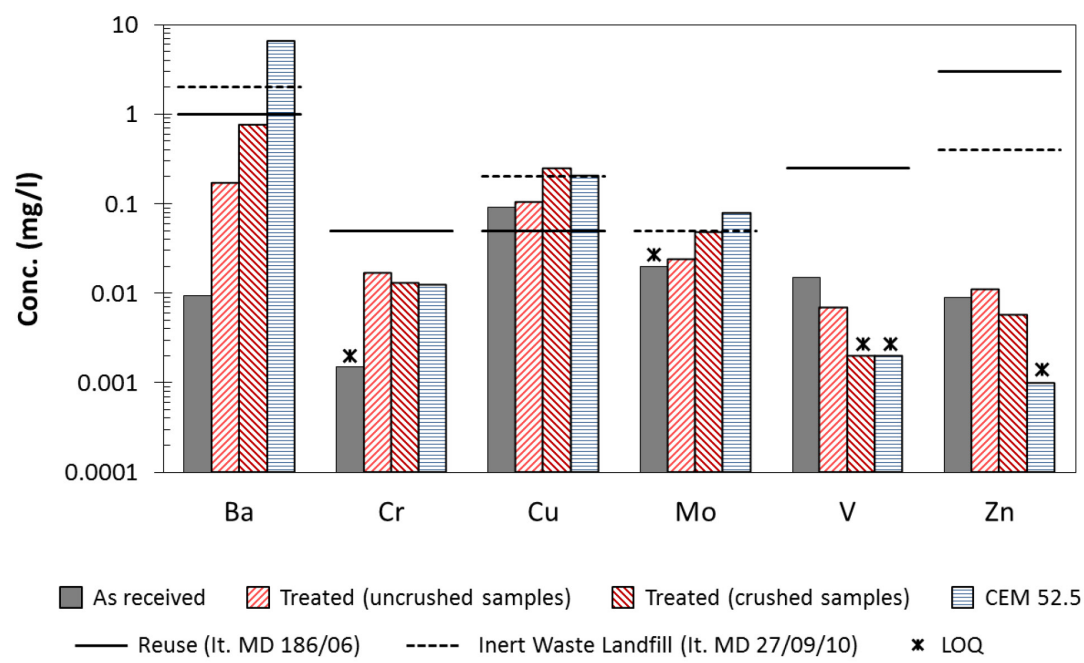

Figure 4: EN 12457-2 leaching test results for the as received industrial soil and the granules obtained after the $\mathrm{S} / \mathrm{S}$-granulation treatment (CEM R 52.5; C/S = 30\% wt.; W/S = 0.17 1/kg; A2/C = 2\%wt.). Data resulting below the instrumental Limit of Quantification (LOQ) are reported as the LOQ value and marked with starred bars in the graph.

Furthermore, the treatment appeared to exert a mobilizing effect also for $\mathrm{Cr}$ and $\mathrm{Cu}$, which, besides the addition of the cement, was correlated to the increase in eluate $\mathrm{pH}$, which may have led to the formation of more soluble phases containing these metals, such as hydroxides [13]. Moreover, $\mathrm{Cu}$ leaching concentrations were found to be comparable to those observed for the eluates of the untreated industrial soil and in both cases they proved higher than the limits established for the reuse of waste materials in simplified procedure (Italian Ministerial Decree 186/06). For the above mentioned metals, as expected, the release increased as particle size decreased, owing to the higher specific surface area available for leaching. From this point of view an unexpected behaviour was found for $\mathrm{V}$ and $\mathrm{Zn}$, since the release of these metals from the crushed samples was observed to be lower than that obtained from the uncrushed ones. Moreover, $\mathrm{V}$ and $\mathrm{Zn}$ release was found to be positively affected by the treatment, since a decrease was observed as a result of the cement-based granulation treatment. Regarding $\mathrm{V}$, its high retention in the cementitious matrix was probably due to the alkaline $\mathrm{pH}$ of the leachate, which is generally associated to minimum solubility values for this metal.

\section{Conclusions}

In this study the effects of a combined S/S-granulation treatment applied to an industrial soil sampled from a brownfield site were assessed in terms of the particle size, mechanical strength and leaching behaviour resulting for the 
produced aggregates. In order to define the preliminary operating windows of this process, screening tests were performed on a non-contaminated natural soil. The results obtained from the treatment of the natural soil showed that, besides other parameters, the type and amount of cement employed were the factors that most influenced the particle size and mechanical strength (measured in terms of ACV) of the aggregates, while the type and amount of superplasticizer proved to be less relevant. Specifically, a $25 \%$ content of high resistance cement (R 52.5) resulted in the production of granules with an ACV comparable to that of natural gravel $(20 \%)$. With regard to the industrial soil, it was found that its characteristics may influence the effectiveness of the applied treatment, as well as the effects of the binder composition on the properties of the resulting product. Indeed, an optimum ACV, similar to that obtained for the natural soil, was achieved by increasing the cement content to $30 \%$ and by employing $2 \%$ of the acrylic-based superplaticizer. Hence, combined S/S-granulation proved to be an effective treatment for obtaining a product with mechanical strengths suitable for construction applications from brownfield contaminated soil; however it proved less efficient in improving the environmental behaviour of the treated soil in terms of the release of certain metals, especially $\mathrm{Cu}$. The increased mobilization of $\mathrm{Cu}, \mathrm{Ba}$, Mo and $\mathrm{Cr}$ was mainly ascribed to the characteristics of the cement used as a binder, which showed to release significant concentrations of these metals. In addition, the leaching of the above mentioned elements is $\mathrm{pH}$ dependent and can increase in the alkaline environment produced as a result of the cement-based treatment.

\section{Acknowledgement}

The authors wish to acknowledge the support received by the Seventh Framework programme of the European Commission within the project Holistic Management of Brownfield Regeneration (HOMBRE).

\section{References}

[1] Baciocchi, R., Capobianco, O. \& Costa, G., Assessment of technology trains for the treatment and reuse of excavated materials in the context of brownfield regeneration. Proc. of the ISWA World Solid Waste Congress. Florence, Italy, 17-19 September, 2012.

[2] Capobianco, O., Costa, G., Thuy, L., Magliocco, E., Hartog, N. \& Baciocchi, R., Carbonation of stainless steel slag in the context of in situ brownfield remediation. Minerals Engineering, in press December 2013, http://dx.doi.org/10.1016/j.mineng.2013.11.005.

[3] Voglar, G.E. \& Leštan, D., Solidification/stabilization of metals contaminated industrial soil from $\mathrm{Zn}$ smelter in Celje, Slovenia, using cement as a hydraulic binder. Journal of Hazardous Materials, 178(1-3), pp. 926-933, 2010. 
[4] Dermatas, D. \& Meng, X., Utilization of fly ash for stabilization/solidification of heavy metal contaminated soils. Engineering Geology, 70(3-4), pp. 377-394, 2003.

[5] Iveson, S.M., Litster, J.D. \& Ennis, B.J., Fundamental studies of granule consolidation Part 1: effects of binder content and binder viscosity. Powder Technology, 88(1), pp. 15-20, 1996.

[6] Iveson, S.M., Litster, J.D., Hapgood, K. \& Ennis, B.J., Nucleation, growth and breakage phenomena in agitated wet granulation process: a review. Powder Technology, 117(1-2), pp. 3-39, 2001.

[7] Scanferla, P., Ferrari, G., Pellay, R., Volpi Ghirardini, A., Zanetto, G. \& Libralato, G., An innovative stabilization/solidification treatment for contaminated soil remediation: demonstration project results. Journal of Soils and Sediments, 9(3), pp. 229-236, 2009.

[8] Cioffi, R., Colangelo, F., Montagnaro, F., \& Santoro, L., Manufacture of artificial aggregate using MSWI bottom ash. Waste Management, 31(2), pp. 281-288, 2011.

[9] Medici, F., Piga, L. \& Rinaldi, G., Behaviour of polyaminophenolic additives in the granulation of lime and fly-ash. Waste Management, 20(7), pp. 491-498, 2000.

[10] Marruzzo, G., Medici, F., Panei, L. \& Rinaldi, G., Characteristics and properties of a mixture containing fly ash, hydrated lime and organic additive. Environmental Engineering Science, 18(3), pp. 159-165, 2001.

[11] Rossetti, V.A., Di Palma, L. \& Medici, F., Production of aggregate from non-metallic automotive shredder residues. Journal of Hazardous Materials, 137(2), pp. 1089-1095.

[12] Stegemann, J.A. \& Zhou, Q., Screening tests for assessing treatability of inorganic industrial wastes by stabilization/solidification with cement. Journal of Hazardous Materials, 161(1), pp. 300-306.

[13] Paria, S. \& Yuet, P.K., Solidification-stabilization of organic and inorganic contaminants using Portland cement: a literature review. Environmental Reviews, 14(4), pp. 217-255. 